\title{
Unwrapping the Cosmetic Package: A Discriminant Analysis Approach
}

\author{
Suraj Kushe Shekhar*, Raveendran $\mathrm{P} \mathrm{T}^{\dagger}$ and Rehin K R
}

\section{Abstract}

Packaging which is often called as the 'silent salesman' is an important component of marketing. Today the importance of packaging has risen to such an extent that product packaging is rightly called as the fifth ' $\mathrm{P}$ ' of marketing mix. Cosmetics are products which are utilized by a large number of people. The present study examines the discriminating power of five selected cosmetics packaging variables namely 'picture', 'colour', 'size', 'shape' and 'material' amidst those who purchased cosmetics based on these packaging variables and for those who purchased cosmetics not based on these packaging variables. Discriminant analysis showed that only two variables namely 'Colour' (.706) and 'Shape' (.527) were good predictors. Variables 'Picture', 'size' and 'material' were considered as poor predictors as far as the student communities were considered. The cross validated classification showed that out of the 240 samples drawn, $91.8 \%$ of the cases were correctly classified.

Keywords: Consumers, Cosmetics, Discriminant analysis, Packaging, Purchase

\footnotetext{
* Junior Research Fellow, Department of Management Studies, Kannur University (DMS, KU), Thalassery Campus, Kannur, Kerala, India; surajkushe@gmail.com

† Professor, DMS, KU;prof.raveendran@gmail.com

‡ Research Scholar, DMS, KU; rehinkr@gmail.com
} 


\section{Introduction}

Product package is regarded as a major component of marketing. In earlier days packaging was regarded as a sheer protective tool but today, it is considered as a major element of the marketing process. Today product package is often positioned as the fifth ' $\mathrm{P}$ ' of the marketing mix. Pilditch (1961) was the first to propose packs as the 'silent salesman'. Lewis (1991) extended Pilditch's (1961) views, describing good packaging as far more than a salesman but a flag of recognition and a symbol of values. Vazquez, Bruce and Studd (2003) mentioned that product package must come alive at the point of purchase, in order to symbolize as the 'salesman'. Richardson et al. (1994) later mentioned packages being associated with the product but with extrinsic properties. Underwood (2003) suggested product packages constituting intrinsic or extrinsic attributes based on certain features they possessed.

Cosmetics generally include skin care and makeup products including perfumes. Few use skin care products only, while others use both skin care products and makeup products. Packaging serves as a good advertising for cosmetics. Cosmetic packaging designs have a hypnotizing effect on the consumer's mind. Today cosmetics appeals to all age groups. Nowadays there are different brands and types of cosmetics in the market. Packaging in the cosmetics industry is critical and also vital when targeted at young consumers. Today cosmetic packages are designed to please different occasions, stimulate different social segments and even distinguish between branded and the unbranded. Some consumers buy cosmetics because of brand, some buy cosmetics because of price, some buy cosmetics because their friends' recommendations and others buy cosmetics because of packaging design. Based on the results from previous researches, this paper makes an attempt to identify the level of influence of five major visual cosmetic (perfumes) packaging variables ('picture', 'colour', 'size', 'shape' and 'material') on young consumers' purchase behaviour. The paper uses a linear discriminant analysis approach to identify which variable/s discriminated between those who purchased cosmetics 
based on packaging variable/s and those who purchased cosmetics not based on packaging variable/s.

\section{Literature Review}

Silayoi and Speece (2007) in their article mentioned that visual components of package influence purchase decisions more than informational elements. Madden et al. (2000) stated the marketers must consider colour as integral part of their marketing strategies. They further opined that taking the colours of a particular logo, package, or product design from one market to another must be done through a thorough understanding of how colours and the colour combinations are perceived in each location. Colour is considered as the most important tool for the emotional expression of a package (Hine, 1995) as it reflected an image for the product (Sauvage, 1996). Underwood (2003) opined that consumers associated meaning to the package colours in three different ways: the 'physiological', the 'cultural', and the 'associational'. The first one has been described as universal and involuntary (e.g. the colour red speeding the pulse). The second one, cultural, occurred over long periods of time in different societies (e.g. the colour black relates to elegance in Europe). The third one, associational, was developed through marketing efforts (e.g. the colour pink relates to the product with low calories). In addition, colour was considered as a tool for brand identification and visual distinction (Underwood, 2003).

Colour was also considered as an important factor for legibility of the texts and comprehension of the images placed on the package. Meyers-Levy and Peracchio (1995) opined that colour, which is assumed to be more vivid than black and white, attracted attention and could provide information. It was observed that a product must stand out from the clutter of the competing brands in order to succeed and colour had a great role to catch the needed attention (Fitzgerald and Russo, 2001; Meyers-Levy and Peracchio, 1995). However it was also perceived that colour attracted attention of irrelevant data in a situation when colorful graphics used consumers' resources in examining the verbal component of the package leading to an incorrect conclusion on the product (Fitzgerald and Russo, 2001). Particularly in a grocery shop, 
consumers relied on cues that they could quickly assess (Richardson et al., 1994) and therefore if the product's colour evoked associations that conflicted with actual product features, the risk of choosing a bad product was possible. The notion of colour associations was found to be quite complex. On the one hand, consumers seemed to have personal and cultural preferences for some colours over others (Grossman and Wisenblit, 1999). On the other hand, entire product classes seemed to have sets of 'acceptable' colours (Schoormans and Robben, 1997) and these sets seemed to be independent of personal colour preferences. According to Grossman and Wisenblit (1999), a favorite colour did not efficiently explain consumer colour choices for products. Consumers developed a wide range of color associations for various product contexts, which made the task of understanding colour responses more complicated. They further added that rather than examining general colour preferences among consumers, it was preferable to learn consumers' colour associations as a basis for understanding the emotional aspects of colour.

Colour associations seems to be influenced by numerous aspects. Ampuero and Vila (2006) found some colour associations which they stated could cross category boundaries. The authors found that packaging in cold and dark colours were usually associated with high-prices and refined aesthetics. In contrast, accessible products that were directed to price sensitive consumers required light, mainly white, colored packaging. Safe and guaranteed products were associated with red packaging. Whether these results demonstrate an innate meaning of colour to consumers or only a set of colour associations learned from existing product categories, however, remains unclear till date.

Size and shape are also crucial dimensions of packaging. Raghubir and Greenleaf (2006) mentioned that consumers used these things as simplifying visual heuristics to make volume judgments. They further explained that even if consumers frequently purchased the same package and had experience using them, they perceived more elongated packages to be better. Thus, elongating the shape, within acceptable bounds, resulted in consumers thinking of the package as better value for money and resulted in larger sales. They further added that disconfirmation of package size after consumption may 
not lead consumers to revise their volume judgment sufficiently in the long term, especially if the discrepancy was not that large. According to Silayoi and Speece (2004), package size, shape, and elongation affected consumer assessment and decisions, much like graphical elements. They found that size and shape were much related to usability. They further argued that when consumers thought of product pictures and graphics being considered as a means of communication, argument about size and shape focused more on packages being convenient to use and carry. Participants opined that packaging size and shape helped them judge product volume and value for money (Silayoi and Speece, 2007). Without their household brands, bigger packages of very low involvement goods such as commodity food products tended to be chosen (Silayoi and Speece, 2004).

According to Prendergast and Pitt (1996), different types of packaging sizes appealed to consumers with different involvement levels. They argued that for some low involvement food products, such as generics, low price was made possible through cost savings created by reduced packaging and promotional expenditures. Since generics were usually packaged in large sizes, this directly catered to the needs of consumers from larger households, who were more inclined in looking for good deals. They found the low price of the generics, in larger packaging, as an attractive offer with superb value for money. It was also implied that when product quality was hard to be determined, the effect of packaging size was much stronger.

According to Rettie and Brewer (2000), pictorial elements on packages largely influenced purchase decision. Further, the placement of these elements also marked significant influence on purchase decisions. Research indicated that brain laterality showed an asymmetry in the perception of the elements in package designs. The recall of packaging elements was likely to be inclined by their lateral position on the package, as well as by other usually distinguished factors, such as font style, size, and colour. Recall was found to be enhanced for verbal stimuli when the copy (picture) was on the right-hand side of the product package, and superior for non-verbal stimuli when it is on the left-hand side of the package. It was thus concluded that in order to maximize 
consumers' recall, pictorial elements on the package had to be placed on the left-hand side of the package. MacInnis and Price (1987) stated that a consumer screening a product picture on a package was more inclined to spontaneously imagine aspects of how a product looked, tasted, felt, smelled, or sounded like than they would with a pictureless package. According to them, the imaging of the individual brand then leaded to fewer brands being evaluated, enhancing the brand's likelihood of purchase. Underwood et al. (2001), on the other hand, stated that the positive influence of package picture was primarily to increase attention to a brand, rather than augment the likelihood of the brand to be chosen. According to them, pictures were considered to be exceedingly vivid stimuli and depicting visual imagery on a package enhanced the product's accessibility to consumers, which did not find to be synonymous with brand choice.

Alternatively, Fitzgerald and Russo (2001) opined a picture's capacity to serve as a framework for interpreting a package's informational components, since pictures, according to them, were likely to be processed prior to other components of a package. Therefore, on one side, a picture could strengthen the informational, for example verbal, stimuli. On the other side, if a package was not carefully designed, the two components could contradict and in that case, Fitzgerald and Russo's (2001) statement implied that the intended informational stimuli would be held back. According to Underwood et al. (2001) the picture could also serve as a source of information to a consumer. Pictorial content conveyed a solid information that was more powerful in the decision making process than more abstract verbal information. A picture could actually show how the product looked like or how it could be served, while verbal information could only describe it (Underwood et al., 2001). Moreover, in categories where product knowledge was lower, the product picture proved to be highly diagnostic (Underwood et al., 2001), as it revealed the unknown product in a way that inspired consumers' mind. Also, if little variance existed in price and perceived quality among brands, a product picture was exceedingly important (Underwood et al., 2001). 
Material is also considered as an important element of package design. Package designers utilize a wide array of materials, including paper, cardboard, plastics, glass, wood, metals, and combinations of all (Fitzgerald and Tsosie, 2004). The nature of contents, functional needs, and the product picture were all considered important while determining the right type of material (Sonsino, 1990; Sauvage, 1996). As the shape of a package generated an idea about the brand and the product, the selected material for a package also affected the consumer's mindset. For example, glass was considered as a high-quality image on consumers' minds, at the same time metal packages had an old fashioned image or plastics were considered as low-quality image for particularly older consumers (Sauvage, 1996). If the shape of a package affected the design of the area used for the label, the material of the label affected the print colours. Despite the differentiation of package design components during the design process, these elements were to be carefully combined to constitute the overall design quality (Sonsino, 1990).

\section{Significance of the Study}

The literature discussed above gives an exhaustive idea ,the extent of importance of visual packaging variables namely 'picture', 'colour', 'size', 'shape' and 'material'. However, the literature only describes the significance of these variables with reference to product packaging in general. So far little empirical evidence exists regarding the impact of these variables on the purchase decisions of cosmetics based on packages. Studies haven't been conducted to find out if these variables clearly discriminated between those who purchased cosmetics based on packages and those who purchased cosmetics not based on packages. The present study would bridge the gap in understanding such a scenario.

\section{Research Methodology}

The present study examines the influence of five cosmetics packaging cues namely 'picture', 'colour', 'size', 'shape' and 'material' that could possibly influence the purchase decision of young consumes in such a scenario. Descriptive type of research (Malhotra, 2004) was designed for the study. The study identified the opinion of young consumers which mainly comprised post 
graduate students. Respondents fell in age group between 20-25 years. Convenient sampling was used as the sampling technique and a total of 240 responses were collected. Primary data was used in the study and data collection was undertaken in the form of a field survey. Data collection was carried out in various colleges in Kannur district, Kerala State, India.

Discriminant analysis is a statistical analysis to predict a categorical dependent variable (called a grouping variable) by one or more continuous or binary independent variables (called predictor variables). Discriminant analysis is used when groups are known a priori (unlike in cluster analysis). Each case has a score on one or more quantitative predictor measures, and a score on a group measure. In simple terms, discriminant function analysis is classification - the act of distributing things into groups, classes or categories of the same type (Discriminant function analysis).

The discriminant function $\mathrm{D}$ which predicts which group the case belongs can be written as

$\mathrm{D}=\mathrm{a}_{1} \mathrm{X}_{1}+\mathrm{a}_{2} \mathrm{X}_{2}+\mathrm{a}_{3} X_{3}+\ldots \ldots \ldots \ldots \ldots+\mathrm{a}_{\mathrm{n}} X_{\mathrm{n}}+\mathrm{k}$

$\mathrm{D} \quad=$ discriminate function

a $\quad=$ discriminant coefficient

$\mathrm{X}=$ consumer's score for that variable

$\mathrm{k}=\mathrm{a}$ constant

$\mathrm{n} \quad=$ total number of predictor variables

A discriminant analysis was carried out on five variables namely 'picture', 'colour', 'size', 'shape' and 'material' (predictor variables). The categorical dependent variable were consumers who bought cosmetics based on packaging variable/s and those who bought cosmetics not based on packaging variable/s. Thus the hypothesis of the entire study was designated as:

H0: Does visual elements allow one to discriminate between those who buy cosmetics based on package and those who purchase cosmetics not based on package?

Data obtained through the survey were subjected to Discriminant analysis using SPSS software package (Version 16). The results were interpreted at 95 percent confidence interval. 


\section{Results and Discussions}

Table 1: Statistics

\begin{tabular}{|l|l|r|r|r|r|}
\hline Response & & \multicolumn{1}{|c|}{ Mean } & $\begin{array}{c}\text { Std. } \\
\text { Deviation }\end{array}$ & \multicolumn{2}{|c|}{ Valid N (listwise) } \\
\hline & & & & Unweighted & Weighted \\
\hline No & Picture & 38.4665 & 9.23647 & 105 & 105.000 \\
\hline & Size & 46.6148 & 11.16826 & 105 & 105.000 \\
\hline & Colour & 19.6848 & 5.23565 & 105 & 105.000 \\
\hline & Shape & 4.8482 & 5.39643 & 105 & 105.000 \\
\hline & Material & 22.6770 & 2.56036 & 105 & 105.000 \\
\hline & Picture & 36.1934 & 8.52325 & 135 & 135.000 \\
\hline & Size & 28.2818 & 6.54159 & 135 & 135.000 \\
\hline & Colour & 28.5028 & 7.25153 & 135 & 135.000 \\
\hline & Shape & 8.3481 & 7.53107 & 135 & 135.000 \\
\hline & Material & 20.6409 & 3.15670 & 135 & 135.000 \\
\hline & Picture & 37.7032 & 9.02823 & 240 & 240.000 \\
\hline & Size & 39.0388 & 13.12921 & 240 & 240.000 \\
\hline & Colour & 23.3288 & 7.52428 & 240 & 240.000 \\
\hline & Shape & 6.2945 & 6.58773 & 240 & 240.000 \\
\hline & Material & 21.8356 & 2.99204 & 240 & 240.000 \\
\hline
\end{tabular}

Table 2: Equality Tests (Group Means)

\begin{tabular}{|l|c|r|r|}
\hline & Wilks' Lambda & \multicolumn{1}{c|}{ F } & \multicolumn{1}{c|}{ Sig. } \\
\hline Picture & .980 & 8.781 & .003 \\
\hline Size & .526 & 392.672 & .000 \\
\hline Colour & .666 & 218.439 & .000 \\
\hline Shape & .931 & 32.109 & .000 \\
\hline Material & .887 & 55.295 & .000 \\
\hline
\end{tabular}

Table 3: Within Groups Matrices (Pooled)

\begin{tabular}{|l|l|r|r|r|r|r|}
\hline & & Picture & \multicolumn{1}{c|}{ Size } & Colour & Shape & Material \\
\hline Correlation & Picture & 1.000 & -.118 & .060 & .042 & .061 \\
\hline & Size & -.118 & 1.000 & .042 & -.143 & -.044 \\
\hline & Colour & .060 & .042 & 1.000 & .118 & .137 \\
\hline & Shape & .042 & -.143 & .118 & 1.000 & .116 \\
\hline & Material & .061 & -.044 & .137 & .116 & 1.000 \\
\hline
\end{tabular}


From Table 1, the mean differences indicated the variables to be good discriminators (between the two groups) as the separation between them was found to be large. Table 2 further supported the existence of strong significant differences (for all the independent variables with 'colour' and 'size' indicating very high values for $\mathrm{F}^{\prime} \mathrm{s}$ ) between means of those who purchased cosmetics based on package and those who purchased cosmetics not based on package. Further, within group matrices (pooled) from Table 3 also indicated the use of these five variables for further analysis as the inter correlation between them were found to be low.

Table 4: Log Determinants

\begin{tabular}{|l|r|r|}
\hline \multicolumn{1}{|c|}{ Response } & Rank & Log Determinant \\
\hline No & 5 & 17.631 \\
\hline Yes & 5 & 18.058 \\
\hline Pooled within-groups & 5 & 18.212 \\
\hline
\end{tabular}

Table 5: Test Results (Box's M)

\begin{tabular}{|l|l|r|}
\hline \multicolumn{2}{|c|}{ Box's M } & 176.474 \\
\hline \multirow{4}{*}{ F } & Approx. & 11,615 \\
\cline { 2 - 3 } & df1 & 15 \\
\cline { 2 - 3 } & df2 & 600825.3 \\
\cline { 2 - 3 } & Sig. & .000 \\
\hline
\end{tabular}

Although the log determinants from Table 4 appeared to be similar across the two groups, the Box's M (Table 5) showed that the assumption of equality of covariance matrices was not met. However as the sample size was 240 which are considered to be large for discriminant analysis, this problem was not regarded as that serious.

Table 6: Canonical Correlation

\begin{tabular}{|l|r|r|r|r|}
\hline Function & Eigenvalue & $\begin{array}{c}\% \\
\text { of Variance }\end{array}$ & $\begin{array}{c}\text { Cumulative } \\
\%\end{array}$ & \multicolumn{2}{c|}{$\begin{array}{c}\text { Canonical } \\
\text { Correlation }\end{array}$} \\
\hline 1 & 1.806 & 100.0 & 100.0 & .802 \\
\hline
\end{tabular}


Table 7: Wilks' Lambda

\begin{tabular}{|c|c|c|c|c|}
\hline Function(s) Test & Wilks' Lambda & Chi-square & df & Sig. \\
\hline 1 & .356 & 447.227 & 5 & .000 \\
\hline
\end{tabular}

The canonical correlation (Table 6) which indicates the relation between the independent variables and the discriminant function revealed that the model explained $64.32 \%$ (canonical correlation $=.802$ ) of the variation in the grouping variable, i.e. whether a customer purchased a cosmetic based on packaging attributes and those who purchased a cosmetic not based on packaging attributes. The Wilks' Lambda value from Table 7 also indicated that $35.6 \%$ of the cases were not explained.

Table 8: Structure Matrix

\begin{tabular}{|l|r|}
\hline \multirow{2}{*}{ Colour } & \multicolumn{1}{|c|}{ Function } \\
\cline { 2 - 2 } & \multicolumn{1}{|c|}{1} \\
\hline Shape & .706 \\
\hline Picture & -.527 \\
\hline Size & .265 \\
\hline Material & -.202 \\
\hline
\end{tabular}

The structure matrix (Table 8) revealed that 'Colour' (high score) and 'Shape' (low score) clearly discriminated between those who purchased cosmetic based on packaging attributes and those who purchased a cosmetic not based on packaging attributes. 'Picture' and 'Material' were positively loaded which indicated these variables being associated with purchase behavior. Size was negatively loaded which indicated that this variable was not associated with purchase behavior. 
Table 9: Canonical Discriminant Function Unstandardized Coefficients

\begin{tabular}{|l|r|}
\hline & \multicolumn{2}{|c|}{ Function } \\
\hline & \multicolumn{2}{|c|}{1} \\
\hline Colour & .024 \\
\hline Shape & .080 \\
\hline
\end{tabular}

From Table 9, the discriminant score for equation (1) is rewritten as

$\mathrm{D}=(.24 \times$ Colour $)+(.080 \times$ Shape $)+(-.100 \times$ Picture $)+(-.012 \times$ Size $)$ $+(.134 \times$ Material $)-4.543$

Table: 10 Group Centroids

\begin{tabular}{|l|r|}
\hline Response & \multicolumn{1}{|c|}{ Function } \\
\hline & \multicolumn{1}{|c|}{1} \\
\hline No & 1.125 \\
\hline Yes & -1.598 \\
\hline
\end{tabular}

Further, the unstandardized canonical discriminant functions evaluated at group means (Table 10) indicated that group centroids closer to 1.125 were purchases not based on packages and group centroids closer to -1.598 were purchases based on packages.

Table 11: Classification

\begin{tabular}{|c|c|c|c|c|c|}
\hline & & Response & \multicolumn{2}{|c|}{$\begin{array}{c}\text { Predicted Group } \\
\text { Membership }\end{array}$} & Total \\
\hline & & & No & Yes & \\
\hline Original & Count & No & 97.3 & 7.7 & 105 \\
\hline & & Yes & 12.6 & 122.4 & 135 \\
\hline & $\%$ & No & 92.6 & 7.4 & 100.0 \\
\hline & & Yes & 9.4 & 90.6 & 100.0 \\
\hline Cross-validated & Count & No & 97.3 & 7.7 & 105 \\
\hline & & Yes & 12.6 & 122.4 & 135 \\
\hline & $\%$ & No & 92.6 & 7.4 & 100.0 \\
\hline & & Yes & 9.4 & 90.6 & 100.0 \\
\hline
\end{tabular}

The results of the classification matrix (Table 11) showed that $91.8 \%$ of respondents were classified correctly into 'purchases not based on packages' or 'purchases based on packages' groups. 'Purchases 
not based on packages' were classified with a slightly better accuracy $(92.6 \%)$ than 'purchases based on packages' (90.6\%).

\section{Conclusions and Limitations:}

A Discriminant analysis was conducted to access whether consumers purchased cosmetics based on package and those who purchased cosmetics not based on package. Predictor variables were 'picture', 'colour', 'size', 'shape' and 'material'. It was observed that there were significant mean differences for all the predictors on the dependent variable. Even though the log determinants were almost similar, Box's M showed that the assumption of equality of covariance matrices was not met. But given the sample size to be 240 which is considered to be large for Discriminant analysis, this problem was not regarded as that serious. The discriminate function showed a significant relationship between the two groups and all the predictors variables accounting for $64.32 \%$ of between group. A closer examination of the structure matrix indicated that only two significant predictors emerged namely 'Colour' (.706) and 'Shape' (-.527) . Other variables namely 'Picture', 'Size' and 'Material' were considered as poor predictors as far as the young consumer segment was considered. The cross validated classification showed that taken as a whole, $91.8 \%$ of the cases were correctly classified. Thus it was concluded that visual elements ('Colour' and 'Shape') clearly discriminated between those who purchased cosmetics based on package and those who purchased cosmetics not based on package.

The study was confined only to a semi urban district of Northern Kerala, Kannur. The sample size drawn was also small. Studies may be extended to a broader region with a bigger sample size. As cosmetic is a type of product which is used irrespective of age barriers, the present study can be made more comprehensive by including older people. Such an in-depth examination would throw more light in understanding the significant differences if any across several demographic factors. An extended study can also be carried out to understand the difference in purchase pattern if any, across young consumers of urban and rural regions. Many insights can also be raveled by extending the study across diverse products/brands and even on unbranded. The consumer behavior 
patterns can be also interpreted with different methods of analysis such as multiple regression, conjoint analysis, SEM analysis, factor analysis, cluster analysis and so on.

\section{References}

Ampuero, O., \& Vila, N. (2006). Consumer perceptions of product packaging. Journal of Consumer Marketing, 23(2), 100-112.

Bone, P. F., \& France, K. R. (2001). Package graphics and consumer product beliefs. Journal of Business and Psychology, 15(3), 467-489.

Discriminant function analysis. (n.d.).Retrieved March 8, 2013, from wikipedia website, http://en.wikipedia.org/wiki/.

Fitzgerald, M., \& Tsosie, T. (2004). Cereal Box Design: An Interdisciplinary Graphics Activity. Tech Directions, 64(1), 22-25.

Grossman, R. P., \& Wisenblit, J. Z. (1999). What we know about consumers' color choices. Journal of marketing practice: Applied marketing science, 5(3), 78-88.

Hine, T. (1995). The Total Package, Little Brown, Boston.

Lewis, M. (1991). Understanding Brands, Kogan Page: London.

MacInnis, D. J., \& Price, L. L. (1987). The role of imagery in information processing: Review and extensions. Journal of Consumer Research, 473-491.

Madden, T. J., Hewett, K., \& Roth, M. S. (2000). Managing images in different cultures: a cross-national study of color meanings and preferences. Journal of international marketing, 90-107.

Malhotra, N. K. (2004). Marketing Research: An Applied Orientation. Pearson Education Inc, New Jersey.

Meyers-Levy, J., \& Peracchio, L. A. (1995). Understanding the effects of color: How the correspondence between available and required resources affects attitudes. Journal of Consumer Research, 121-138.

Pilditch, J. (1961). The silent salesman: How to develop packaging that sells, Business Publications.

Prendergast, P. G., \& Pitt, L. (1996).Packaging, Marketing, Logistics and the Environment: are there Trade-offs? International Journal of Physical Distribution \& Logistics Management , 26(6), 60-72.

Raghubir, P., \& Greenleaf, E. A. (2006). Ratios in Proportion: What Should the Shape of the Package be? Journal of Marketing, 95-107. 
Rettie, R., \& Brewer, C. (2000). The verbal and visual components of package design. Journal of Product $\mathcal{E}$ Brand Management, 9(1), 5670 .

Richardson, P. S., Dick, A. S., \& Jain, A. K. (1994). Extrinsic and intrinsic cue effects on perceptions of store brand quality. The Journal of Marketing, 28-36.

Sauvage, F. (1996). Food packaging technology, VHC Publishers, United States.

Schoormans, J. P., \& Robben, H. S. (1997). The effect of new package design on product attention, categorization and evaluation. Journal of Economic Psychology, 18(2), 271-287.

Silayoi, P., \& Speece, M. (2004). Packaging and purchase decisions: an exploratory study on the impact of involvement level and time pressure. British food journal, 106(8), 607-628.

Silayoi, P., \& Speece, M. (2007). The importance of packaging attributes: a conjoint analysis approach. European Journal of Marketing, 41(11/12), 1495-1517.

Sonsino, S. (1990). Packaging Design: Graphics, Materials, Technology, Thames and Hudson, London.

Underwood, R. L. (2003). The communicative power of product packaging: creating brand identity via lived and mediated experience. Journal of Marketing Theory and Practice, 62-76.

Underwood, R. L., Klein, N. M., \& Burke, R. R. (2001). Packaging communication: attentional effects of product imagery. Journal of Product \& Brand Management, 10(7), 403-422.

Vazquez, D., Bruce, M., \& Studd, R. (2003). A case study exploring the packaging design management process within a UK food retailer. British Food Journal, 105(9), 602-617. 